\title{
Coupling Fuzzy logic and Analytical Hierarchy Process (FAHP) with GIS for Landslide Susceptibility Mapping (LSM) in Ziz upper watershed, SE Morocco
}

Mohamed Manaouch ( $\square$ mohamed.manaouch@uit.ac.ma )

Universite Ibn Tofail Kenitra https://orcid.org/0000-0002-2362-7098

\section{Sadiki Mohamed}

Universite Ibn Tofail Kenitra

\section{Fenjiro Imad}

Universite Ibn Tofail Kenitra

\section{Research Article}

Keywords: Landslides susceptibility, Fuzzy Analytical Hierarchy Process, GIS, Ziz watershed, Southeast Morocco Posted Date: February 23rd, 2021

DOl: https://doi.org/10.21203/rs.3.rs-183793/v1

License: (a) (i) This work is licensed under a Creative Commons Attribution 4.0 International License. Read Full License 


\section{Abstract}

Landslides have become a destructive geo-hazard in many countries, which seriously cause damage to the human lives, infrastructure and properties. They result from the movement of soil on unstable slopes in mountainous areas. This caught attention to study the increasing incidences of landslides in many areas including Morocco. In this study, the fuzzy logic and analytical hierarchy process (FAHP) integrated with the geographic information system (GIS) are used to determinate the landslide susceptibility modeling in the Ziz upper watershed, southeast Morocco. The geo-environmental data that were used in the landslide susceptibility mapping (LSM) included: elevation, lithology, slope, land use/land cover (LULC), river, road, fault, and rainfall maps. FAHP model showed that $16.7 \%$ of the study area had high landslide susceptibility. However, the riskiest areas are situated in the upstream western parts. The resultant map of landslides hazards was validated using an inventory of 148 landslides events in the study area. The FAHP model showed a significant performance, the area under curve (AUC) value for this case study is 0.885 .

\section{Introduction}

Landslides are formed on slopes as a result of the downslope mass-movements of rock, earth, and debris, under the direct effect of gravity or triggered by external factors such as earthquakes and rainfall. They are one of the most common natural hazards everywhere in Iran (Bahrami et al. 2020; Pourghasemi et al. 2012; Mansouri Daneshvar 2014), Kenya (Tan et al. 2020), Algeria (Achour et al. 2017), Serbia (Dokanovic 2019), India (Saha and Roy 2019), Japan (Yoshimatsu and Abe 2006), China (Dai and Lee 2001a), Korea (Lee and Min 2001), Malaysia (Lee and Pradham 2007), Turkey (Akgun and Bulut 2007), USA (Wachal and Hudak 2000), Italy (Pellicani et al. 2014), Austria (Zieher et al. 2016) and many others... These landslides cause a large number of deaths worldwide (Flentje and Chowdhury 2016) and endanger properties, facilities, roads, forests and agricultural fields. So, it is very important to predict landslide-prone areas and where it can occur in the future for reducing the detriments.

Numerous methods have been proposed and including both qualitative and quantitative approaches for mapping landslide susceptibility. Each of the methods mentioned has both advantages and drawbacks.

Nowadays, the fundamental role of the GIS in which several geo-data can be visualized, processed and analyzed with the increasing availability of geospatial data and rapid developments in computational science, numerous LSM methods have been proposed. Most of these methods were built on GISs known as GIS-based Multi-Criteria Decision Making (MCDM) methods which are valuable and ingenious approaches to change either spatial or nonspatial data into desired information that along with subjective judgments of decisionmakers in crucial decisions (Sumathi et al. 2008; Chen et al. 2010).

In the literature, several different methods and techniques for LSM have been tested. Many studies have evaluated landslide susceptibility using GIS and MCDM methods such as fuzzy logic (Saboya et al 2006), AHP, analytic network process (Yalcin 2008), weighted linear combination, logistic regression (Akgun and Bulut 2007) and multivariate statistical approach (Van Westen et al. 1997). But, both AHP and fuzzy logic are two popular and prevalent GIS-based methods that have been widely and successfully applied (Lai 1995).

In Morocco there are no examples for LSM studies. So, there are two novelties in this study: (i) no previous studies have been conducted in this area, this is the first one, while present study covers the whole area of Ziz upper 
watershed (approximately $4435 \mathrm{~km}^{2}$ ) and (ii) this article is based on the integration of combined fuzzy logic and AHP for LSM using nine triggering factors in landslide occurrence.

The production process of LSM requires the evaluation and analysis of all influencing factors together. Therefore, providing a database of influencing factors in landslide occurrence is the essential step in the LSM's production. On this subject, nine contributing factors (including fault, stream, road, slope, rainfall, LULC, aspect, elevation and lithology) were weighted according to the judgments of geoscientists and many studies in modelling landslide occurrences. The factor's maps were prepared then integrated by using FAHP to map landslide susceptibility in the study area. In order to validate the generated map produced by FAHP model, the receiver operating characteristic (ROC) curve was applied in the verification process.

So, the main objective of this research is to apply the GIS-FAHP approach for LSM in the Ziz upper watershed. The landslide influencing factors were collected from a variety of sources and the landslide inventory used in this work was prepared from google earth images, and field surveys. Additionally, the resulted map serves as a useful tool for the authorities involved in land planning to prevent material and moral losses.

\section{Materials And Methods}

\subsection{Study area}

The study area is located in southeast of Morocco. It has an area of about $4435 \mathrm{~km}^{2}$, and is located at longitude of $32^{\circ} 05^{\prime} 48$ " to $32^{\circ} 64^{\prime} 19^{\prime \prime} \mathrm{N}$ and latitude of $04^{\circ} 11^{\prime} 72^{\prime \prime}$ to $05^{\circ} 46^{\prime} 20^{\prime \prime} \mathrm{W}$ (Fig. 1). The altitude is between 1023 and $3687 \mathrm{~m}$ above sea level. According to climatic data, the study area's climate is semi-arid, characterized by a harsh winter and a moderate summer with hot temperatures varying depending on the altitude. Annual precipitation ranges from 119 to $377 \mathrm{~mm}$. $\mathrm{yr}^{-1}$ (Manaouch et al. 2020). Average annual temperatures vary between $19.2^{\circ} \mathrm{C}$ and $10.2^{\circ} \mathrm{C}$. The soils represented are almost little developed: eroded, alluvial or colluvial soils in deposit areas, or even raw minerals not yet developed in mountain peaks and rocky areas. The lithology is largely dominated by the Jurassic marl-limestone layers (Charire 1990; Hinaje 1995; Sadki et al. 1999) and continental backfill formations of the Plio-quaternaries (Fig. 2E) (PNABV 2014). For LULC, five types were identified: agricultural fields occupy the banks of watercourses; water bodies represented exclusively by the reservoir of the dam; degraded forest limited to the Atlas cedars, Phenician juniper, Thuriferous juniper, Holm oak and Aleppo pine and thorny xerophytes and finally rangeland which is very largely dominant (Manaouch et al. 2020). Due to the conditions cited above, the study area is exposed to landslides. Therefore, to forecast the landslide susceptibility, data on the elevation, aspect, lithology, slope, LULC, streams, road, fault, rainfall maps were collected and prepared.

\subsection{Data source}

In this study, the used topographic data (aspect, slope and stream) was extracted by ArcGIS 10.5 from a digital elevation model (DEM) of the Scuttle Radar Topographic Mission (SRTM) with resolution of 30m. The lithology and faults were prepared from geological maps. The rainfall data was calculated from four meteorological stations. LULC map was extracted by processing satellite images of Landsat 8 Operational Land Imager (OLI) acquired in mars 2017 (Manaouch et al. 2020). Roads map was prepared from Base map of ArcGIS 10.5 in 2020. The following table provides more details on the data source used in this work. 


\begin{tabular}{|c|c|c|}
\hline Dataset & Year & Format \\
\hline Monthly rainfall Data ${ }^{1}$ & 1976 to 2019 & Digital excel \\
\hline Geological maps ${ }^{2}$ & $1939 \& 1956$ & Digital vector \\
\hline Landsat $8 \mathrm{OLI}^{3}$ & 2017 & Digital raster \\
\hline DEM - SRTM ${ }^{3}$ & 2017 & Digital raster \\
\hline Base map 4 & 2020 & Digital vector \\
\hline Google earth image ${ }^{5}$ & 2018 & Digital raster \\
\hline
\end{tabular}

Table 1 Data source used in this study.

${ }^{1}$ Guir-Ziz-Rhris watershed agency (ABH-GZR 2019)

${ }^{2}$ Geological map of Midelt high Atlas (Gonzague et al. 1939) and Geological map of high Atlas north Ksaressouk and Boudenib (Lyazidi et al. 1956)

${ }^{3}$ www.earthexplorer.usgs.gov

${ }^{4}$ Base map in ArcGIS 10.5

${ }^{5}$ Google earth.

\subsection{Preparation of the landslide inventory map}

The landslide inventory map is the most important part for identifying the landslide hazards zones (Pourghasimi et al. 2012). It can be prepared by using different data such as historical landslide events, satellite image analysis and field survey (Fig. 1). In this work, 148 landslides have been identified from Google earth imagery and multiple field visits. Then, this inventory has been prepared in the GIS environment to determine both the relationship between the factors affecting the landslide's incidence and the importance of each factor in landslide occurrence (Yalcin et al. 2011). Moreover, the landslide inventory was used to validate the LSM generated by FAHP model.

\subsection{Fuzzy method}

In the classical set theory, the membership value of 1 for an object means that it is a member of a set and the value of 0 means that it is not a member of a set (Hines 1997). In 1965, Zadeh introduced the fuzzy set theory that is one of the widely used approaches in many scientific researches in different disciplines. Therefore, the use of fuzzy logic in geo-sciences is to consider the spatial objects on a map as the members of a set. In landslide susceptibility studies, the use of the fuzzy logic approach consists of considering the pixels on any causal factor layer as a member of landslide susceptibility. Pixel values range from 0 which means it is not member "not susceptible" to 1 which means it is a full member "susceptible". Therefore, by Transforming the input raster maps into a 0 to 1 scale, indicating the robustness of a membership in a landslide susceptibility "set", based on fuzzy algorithms. 
In this study, a linear membership function (LMF) was used for preparing fuzzy maps for each factor. This membership function (MF) gives to each parameter a value ranging between 0 and 1 (Zadeh 1965). If x "factor" value equal 0 that means is not a member of the landslide susceptibility and if this $x$ "factor" value equal 1 that means is a full member of the landslide susceptibility. More explanation of fuzzy logic set is shown in the following equations (McBratney and Odeh 1997):

$A=\left\{x, \mu_{A}(x)\right\}$ for each $x \in X$

Where $f(A)$ is the MF of $x$ in fuzzy logic set $A$ then:

If $x$ does not belong to $A$ then $A=0$.

If $\mathrm{x}$ belongs completely to $\mathrm{A}$ then $\mathrm{A}=1$.

If $x$ belongs in a certain degree to $A$ then $0<A(x)<1$.

From Equation above, LMF was used for some geo-environmental factors slope, elevation, lithology, LULC, aspect, and rainfall (Feizizadeh and Blaschke 2013).

$$
\mu_{\mathrm{A}}(\mathrm{x})=\mathrm{f}(\mathrm{x})=\left\{\begin{array}{lc}
0 & x \leq a \\
\frac{x-a}{b-a} & a<x<b \\
1 & x \geq b
\end{array}\right\}
$$

Where $\mathrm{x}$ is the input data and $\mathrm{a}$, bare the min and max values, respectively.

For assessing the effect of the distance to river, distance to fault, and distance to road on landslides susceptibility, the following LMF was used (Feizizadeh and Blaschke 2013)

$$
\mu_{\mathrm{A}}(\mathrm{x})=\mathrm{f}(\mathrm{x})=\left\{\begin{array}{lc}
0 & x \leq a \\
\frac{b-x}{b-a} & a<x<b \\
1 & x \geq b
\end{array}\right\}
$$

Where $\mathrm{x}$ is the value of distance to river, distance to fault, and distance to road and $\mathrm{a}, \mathrm{b}$ are the limits values. In this paper, nine factors for LSM were used: DEM, aspect, slope, lithology, rainfall, LULC, distance to faults, distance to roads and distance to rivers. Fuzzy map for each factor was prepared.

Table 2 Maximum and minimum values of criteria (Feizizadeh and Blaschke 2013). 


\begin{tabular}{lll}
\hline Parameters & Minimum & Maximum \\
\hline LULC & Water bodies, Agricultural fields & Degraded forest, Rangeland \\
Rainfall (mm) & $<100$ & $>400$ \\
Distance to roads (m) & $>100$ & $<25$ \\
Distance to streams (m) & $>200$ & $<50$ \\
Distance to faults (m) & $>4000$ & $<1000$ \\
Lithology (Soil Erodibility factor) & 0.16 & 0.05 \\
Aspect & Flat & South \\
DEM $(\mathrm{m})$ & $<1200$ & $>3000$ \\
Slope $\left({ }^{\circ}\right)$ & $<10$ & $>40$ \\
\hline
\end{tabular}

Table 3 Distance to fault, stream, and road for determination of landslide susceptibility

\begin{tabular}{|c|c|c|c|c|}
\hline \multicolumn{5}{|l|}{ Feature } \\
\hline \multicolumn{5}{|c|}{ Distance to faults (m) } \\
\hline $0-1000$ & $1000-2000$ & $2000-3000$ & $3000-4000$ & $>4000$ \\
\hline \multicolumn{5}{|c|}{ Distance to streams (m) } \\
\hline $0-50$ & $50-100$ & $100-150$ & $150-200$ & $>200$ \\
\hline \multicolumn{5}{|c|}{ Distance to roads (m) } \\
\hline $0-25$ & $25-50$ & $50-75$ & $75-100$ & $>100$ \\
\hline
\end{tabular}

\subsection{Analytical Hierarchy Process (AHP)}

AHP is multicriteria decision method (MCDM) implemented by Saaty in 1980. It is applied to determine the criteria weights by using a pairwise comparison method for individual or group of factors. In a pairwise each factor is rated against every other factor by assigning a relative dominant value between 1 and 9 . Description of compared factors is shown in Table1.

\begin{tabular}{|ll|}
\hline Intensity of importance & Definition \\
\hline 1 & Equal importance \\
3 & Moderate importance of one over another \\
5 & Essential importance \\
7 & Demonstrated importance \\
9 & Absolute importance \\
$2,4,6,8$ & Intermediate values between the two adjacent judgments \\
\hline
\end{tabular}

Table 4 Scales for pairwise comparisons (Saaty, 1980)

Pairwise comparisons were applied to produce a matrix by transferring qualitative data into quantitative rates as follows: 


$$
\begin{aligned}
A=\left\{a_{i j}\right\}_{n \times n} & =\left[\begin{array}{ccc}
1 & \cdots & a_{1 n} \\
\vdots & \ddots & \vdots \\
a_{n 1} & \cdots & 1
\end{array}\right]=\left[\begin{array}{ccc}
1 & \cdots & \frac{w_{1}}{w_{n}} \\
\vdots & \ddots & \vdots \\
\frac{w_{n}}{w_{1}} & \cdots & 1
\end{array}\right] \\
a_{i j=\frac{a_{i j}}{\sum_{i=1}^{n} a_{i j}}} & i, j=1,23, \ldots n \\
w_{i} & =\left(\frac{1}{n}\right) \sum_{j=n}^{n} a_{i j} \quad i=1,2, \ldots . n
\end{aligned}
$$

In this study, a total of nine geo-environmental factors were used including DEM, aspect, lithology, slope, rainfall, distance to rivers, distance to roads and distance to faults. According to the Saaty scale and based on the subjective judgments of the geoscientist to obtain the factor's weight, a number ranging from 1 to 9 was assigned for each factor. These factors weights mean their relative importance to landslides susceptibility according to the

\begin{tabular}{|c|c|c|c|c|c|c|c|c|c|c|}
\hline & Lithology & Rainfall & LULC & Slope & $\begin{array}{l}\mathrm{d} \text { to } \\
\text { Faults }\end{array}$ & $\begin{array}{l}\mathrm{d} \text { to } \\
\text { streams }\end{array}$ & $\begin{array}{l}\mathrm{d} \text { to } \\
\text { roads }\end{array}$ & Aspect & DEM & Weight \\
\hline Lithology & 1 & 2 & 3 & 4 & 5 & 6 & 7 & 8 & 9 & 0.31 \\
\hline Rainfall & $1 / 2$ & 1 & 2 & 3 & 4 & 5 & 6 & 7 & 8 & 0.22 \\
\hline LULC & $1 / 3$ & $1 / 2$ & 1 & 2 & 3 & 4 & 5 & 6 & 7 & 0.15 \\
\hline Slope & $1 / 4$ & $1 / 3$ & $1 / 2$ & 1 & 2 & 3 & 4 & 5 & 6 & 0.11 \\
\hline $\begin{array}{l}d \text { to } \\
\text { faults }\end{array}$ & $1 / 5$ & $1 / 4$ & $1 / 3$ & $1 / 2$ & 1 & 2 & 3 & 4 & 5 & 0.08 \\
\hline $\begin{array}{l}\text { dto } \\
\text { streams }\end{array}$ & $1 / 6$ & $1 / 5$ & $1 / 4$ & $1 / 3$ & $1 / 2$ & 1 & 2 & 3 & 4 & 0.05 \\
\hline $\begin{array}{l}\mathrm{d} \text { to } \\
\text { roads }\end{array}$ & $1 / 7$ & $1 / 6$ & $1 / 5$ & $1 / 4$ & $1 / 3$ & $1 / 2$ & 1 & 2 & 3 & 0.04 \\
\hline Aspect & $1 / 8$ & $1 / 7$ & $1 / 6$ & $1 / 5$ & $1 / 4$ & $1 / 3$ & $1 / 2$ & 1 & 2 & 0.03 \\
\hline DEM & $1 / 9$ & $1 / 8$ & $1 / 7$ & $1 / 6$ & $1 / 5$ & $1 / 4$ & $1 / 3$ & $1 / 2$ & 1 & 0.02 \\
\hline
\end{tabular}
expert's opinion.

Table 5 Pairwise comparison matrix, factor weights and consistency ratio of the data layers used.

\section{Results And Discussion}

\subsection{Preparing raster maps}

For determining the LSM of the Ziz upper watershed, the application of the FAHP model requires the preparation of the thematic maps, each representing the input data known as the DEM, aspect, lithology (soil erodibility), fault, slope, LULC, streams, road, and rainfall maps that are shown in Fig. 2. Once database was created, a resolution of $30 \mathrm{~m}$ was preferred corresponding to the DEM-SRTM resolution. 
According to the input raster maps, the elevation varies from $1023 \mathrm{~m}$ (above sea level) in the catchment outlet to $3687 \mathrm{~m}$ in the north-western part with an average altitude of $1812 \mathrm{~m}$ (Fig. 2). Besides, the slope value is between 0.004 and $66.08^{\circ}$ and the dominant slope class is between 0 and $15^{\circ}$, it represents $82 \%$. The aspect value is between - 1 (flat) and 360 (north) in which aspects of the north and the west that receive significant precipitations are sensitive to landslide. Rainfall map was developed based on four meteorological stations datasets, located in the watershed. Spatial distribution of rainfall was estimated by the interpolation method IDW (Inverse Distance Weighted), which allow estimating the values of any point. The rainfall value ranges from 120 to $470 \mathrm{~mm}$. $\mathrm{yr}^{-1}$. Low values occupy the southern and eastern parts. However, high values are observed in the western watershed borders (Fig. 2B). The highest values are located in the western and northwestern parts, representing respectively the upstream mountainous areas (Fig 2A). According to Fig. $2 \mathrm{~F}$ in the study area, there are five types of LULC (degraded forest, agricultural fields, poorly vegetated areas (rangelands),water bodies and built-up areas). Finally, the soil erodibility factor was used for assessing the sensitivity of lithology to landslide (Manaouch et al. 2020). According to Fig. 2E, if the soil erodibility factor is low, sensitivity to landslide is high.

The last method in the LSM process was the raster maps preparation of distance to road, distance to fault and distance to streams. These three maps have been prepared with the help of Euclidian distance buffering tool in ArcGIS 10.5 software as shown in table 3 and (Fig. 2G, H, I). Then, the integration of all these maps in ArcGIS 10.5 software allowed us to obtain a final map of landslides prone-areas.

\subsection{Fuzzy method}

For determining the fuzzy map of each parameter, LMF option in ArcGIS 10.5 software was used. The lowest and highest value of LMF are illustrated in Tables 2 and 3. According to these results, LMF was defined for each parameter between 0 and 1. For example the DEMs higher than $3000 \mathrm{~m}$ their value is 1 and for those smaller than $1000 \mathrm{~m}$ their value is 0 . So, LMF is measured and ranges between 0 and 1 for the DEM values between 1000 and $3000 \mathrm{~m}$. In the same way and based on Tables 2 and 3, the LMF was defined for all other parameters between 0 and 1. The fuzzy maps prepared for the landslide susceptibility parameters are shown in Fig. 3, where LMF is closer to 0 with decreasing the landslide susceptibility whereas LMF is closer to 1 with increasing the landslide susceptibility. According to Fig. 3 all parameters (aspect, distance from road, distance from stream, distance from fault, slope, DEM, LULC, rainfall, and lithology) were closer to 1 in the upstream western parts of the study area.

\subsection{AHP method}

In the present study, AHP method was used to incorporate different types of input data by using the pairwise comparison method (Feizizadeh and Blaschke 2013). According to Table 5, the lithology and DEM have the highest and lowest weight, respectively. Then, the highest significance is given to lithology (0.31) and rainfall (0.22). The least significance is given to aspect (0.03) and elevation (0.02).

\subsection{FAHP model}

The integration of FAHP with GIS provides a good tool for mapping landslide susceptibility. Then, the weights of parameters, calculated by AHP method, have been integrated with fuzzy maps of selected parameters to generate LSM with the help of raster calculator of spatial analyst tool in ArcGIS10.5 software.

According to the resultant map (Fig. 4), the susceptibility conditions are very high in the western upstream parts and northern parts of the study area. These areas are mainly dominated by mountainous rangelands. Moderate 
landslide susceptible zones are shown to be widely distributed in the eastern, southern and central parts of the study area. The low and very low landslide susceptible areas are mainly distributed in the northwestern and some central zones.

The final landslide susceptibility map (Fig. 4) was reclassified based on the most used method of natural break (Pourghasemi et al. 2012) into four relative susceptibility zones like very low, low, medium and high as shown in Fig. 5.

Based on Fig. 5 and the graph of Fig. 6, the percentage values of areas covered with various landslide susceptibility for FAHP model are as follows: (High = 16.7\%), (Medium = 36.1\%), (Low = 25\%) and (Very Low = $22.2 \%)$.

\subsection{LSM validation}

To validate the model's accuracy, there are many methods. In this study, the validation process was based on the receiver operating characteristics $(\mathrm{ROC})$ by comparing the classified map with the existing landslides locations in the study area. For this purpose, each pixel value in the predicted map was classified into very low, low, medium and high susceptibility. Then, the ROC curve was used, and the area under curve (AUC) value was calculated by using the ArcSDTM software package. This AUC represents the model's accuracy for predicting the landslides occurrence (Chen et al. 2016). A good fit model has AUC values that range from 0.5 to 1 , while values below 0.5 represent a random fit.

The AUC found in this study has a value of 0.885 , which corresponds to the prediction accuracy of $88.5 \%$. These results show that the FAHP model was a useful tool for predicting landslide prone-areas in this case study.

\section{Conclusions}

Landslides are the most geo-hazards in mountainous areas. Their assessment should be done correctly before their occurrences. Due to the accessibility and variety of remote sensing and GIS data, landslides susceptibility studies can be done easily. In this regard, FAHP model was applied to generate LSM in the large watershed of Ziz, SE Morocco. For this purpose, a landslide inventory map was prepared using 148 landslide events. According to landslide inventory, the most important factors in landslide susceptibility were lithology and rainfall. Whereas, the least important parameters were DEM and aspect. For combining the fuzzy logic and AHP methods, nine factors were evaluated and then weighted. The classified map of landslide susceptibility predicted by FAHP model shows for each pixel that $16.7 \%$ of the lands had high landslide susceptibility, $36.1 \%$ medium landslide susceptibility, $25 \%$ low landslide susceptibility and $22.2 \%$ very low susceptibility. The LSM validation using the ROC/AUC curves show that FAHP model was successfully applied in Ziz upper watershed (success rate 88.5\%). This means that FAHP model was suitable for investigation of LSM; it provided a good result that really agree with the known landslide events. So, the FAHP model produce LSM as a good tool for decision maker to avoid the riskiest susceptible zones, by suitable preventive measures.

\section{Declarations}

\section{Acknowledgements}


The authors would like to thanks all personal of the Watershed Agency of Ziz-Guir-Ghris in Errachidia for providing Data and their kind help. We are grateful to Mr. N. Khan who helped us to validate a predicted result.

\section{References}

ABH-GZR (2019) Agence du bassin hydraulique de Guir-Ziz-Ghris. Errachidia, Morocco. Available at: http://www.abhgzr.ma

Achour Y, Boumezbour A, Hadji R, Chouabbi A, Cavalleiro V, Bendaoud EA (2017) Landslide susceptibility mapping using analytic hierarchy process and information value methods along a highway road section in Constantine, Algeria. Arab J Geosci10:194. https://doi.org/10.1007/s12517-017-2980-6

Akgun A, Bulut F (2007) GIS based landslide hazard for Arsin-Yomra (Trabzon, north Turkey) region. Environmental Geology 51:1377-1387.

Bahrami Y, Hassani H, Maghsoudi A (2020) Landslide susceptibility mapping using AHP and fuzzy methods in the Gilan province, Iran. GeoJournal. https://doi.org/10.1007/s10708-020-10162-y

Charrire A (1990) Héritage hercynien et évolution géodynamique alpine d'une chaine intracontinentale : le Moyen Atlas au $S$ de Fès (Maroc). Thèse Doct Etat, Toulouse.

Chen Y, Yu J, Khan S (2010) Spatial sensitivity analysis of multi-criteria weights in GIS-based land suitability evaluation. Environmental Modelling \& Software 25(12):1582-1591.

Chen W, Chai H, Zhao Z, Wang Q, Hong H (2016) Landslide susceptibility mapping based on GIS and support vector machine models for the Qianyang County, China. Environ Earth Sci 75(6):1-13.

Dai F, Lee C (2001a) Terrain based mapping of landslide susceptibility using a Geographical information system: a case study. Canadian Geotechnical Journal 38:911-923.

Dokanovic S (2019) Landslide susceptibility mapping of SE Serbia using GIS. GEOLOŠKI ANALIBALKANSKOGA POLUOSTRVA 80 (2):105-116 https://doi.org/10.2298/GABP1902105D

Feizizadeh B, Blaschke T (2013) GIS-multicriteria decision analysis for landslide susceptibility mapping: comparing three methods for the Urmia lake basin, Iran. Nat Hazards 65(3):2105-2128. https://doi.org/10.1007/s11069-012-0463-3

Flentje P, Chowdhury R (2016) Resilience and sustainability in the management of landslides. In Proceedings of the institution of civil engineers-engineering sustainability (pp. 1-12). Thomas Telford Ltd.

Hinaje S (1995) Apport de l'analyse de la tectonique cassante tardi et post-panafricane à la modélisation de la mise en place des miniralisations dans la boutoniére de Bou-Azzer (Anti-Atlas, Maroc). Thèse de 3ème cycle, Fac. Sci. Rabat.

Hines JW (1997) Fuzzy and neural approaches in engineering. Wiley, New York, NY

Gonzague D, Despujols M (1939) Carte géologique de Midelt au 1/200 000 publiée par le service géologique du Maroc. 
Lai S (1995) A preference-based interpretation of AHP. Omega 23(4):453-462

Lee S, Min K (2001) Statistical analysis of landslide susceptibility at Yogin, korea. Environmental Geology 40:1095-1113.

Lee S, Pradhan B (2007) Landslide hazard mapping at Selangor, malaysia using frequency ratio and logistic regression models. Landslides 4:33-41.

Lyazidi M, Eyssautier L, Marcais J, Choubert G, Faillot P (1956) Carte géologique de Rich et Boudnib au1/200 000 publiée par le service géologique du Maroc.

Mansouri Daneshvar MR (2014) Landslides susceptibility zonation using analytical hierarchy process and GIS for the bojnurd region, northeast of Iran. Landslides 11:1079-1091.

Mohamed M, Anis Z, Imed F (2020) Regional-scale modeling of water erosion and sediment yield in a semi-arid context: A case study of Ziz upper watershed in south-eastern Morocco. GEOIT4W-2020: Proceedings of the 4th Edition of International Conference on GeolT and Water Resources 2020, Al-Hoceima, Morocco, March 11 -12, 2020.http://doi.org/10.1145/3399205.3399209

Mohamed M, Anis Z, Imad F (2020) Assessment of the Effects of Land Use/Land Cover Changes on Soil Loss and Sediment Yield Using WaTEM/SEDEM Model: Case Study of Ziz Upper Watershed in SE-Morocco. Current Applied Science and Technology 21(2):337-350.

MycBratney AB, Odeh IOA (1997) Application of fuzzy sets in soil science: fuzzy logic, fuzzy measurements and fuzzy decisions. Geoderma 77:85-113.

Pellicani R, Van Westen S, Spilatro G (2014) Assessing landslide exposure in areas with limited landslide information. Landslides 11:463-480.

PNABV (2014) Plan National d'Aménagement des Bassins Versants, Étude d’aménagement du bassin versant d’Assif Melloul, Agence du Bassin Hydraulique de l'Oum Er-Rbia.

Pourghasemi HR, Mohammady M, Pradhan B (2012) Landslide susceptibility mapping using index of entropy and conditional probability models in GIS: Safarood Basin, Iran. Catena 97:71-84.

https://doi.org/10.1016/j.catena.2012.05.005.

Pourghasemi HR, Pradhan B, Gokceoglu C (2012) Application of fuzzy logic and analytical hierarchy process (AHP) to landslide susceptibility mapping at Haraz watershed, Iran. Nat Hazards 63(2):965- 996.

Saaty TL (1980) The analytical hierarchy process, 350. New York: McGraw Hill.

Saboya F, Alves MG, Pinto WD (2006) Assessment of failure susceptibility of soil slopes using fuzzy logic. Engineering Geology86:211-224.

Sadki D, Elmi S, Amhoud H (1999) Les formations jurassiques du Haut Atlas central marocain : corrélation et évolution géodynamique. Le 1er Coll. Nat. Sur le Jur. Marocain, pp 122-123. 
Saha S, Roy J (2019) Landslide susceptibility mapping using knowledge driven statistical models in Darjeeling District, West Bengal, India. Geoenvironmental Disasters 6:11 https://doi.org/10.1186/s40677-019-0126-8

Sumathi VR, Natesan U, Sarkar C (2008) GIS-based approach for optimized siting of municipal solid waste landfill. Waste Management 28(11):2146-2160.

Tan X, Zhou S, Zhou S (2020) Nationwide Susceptibility Mapping of Landslides in Kenya Using the Fuzzy Analytic Hierarchy Process Model. Land 9:535. https://doi:10.3390/land9120535

Van Westen CJ, Rengers N, Terlien TJ, Soeters R (1997) Prediction of the occurrence of slope instability phenomena through GIS-based hazard zonation. Geologische Rundschau 86:404-414.

Wachal DJ, Hudak PF (2000) mapping landslide susceptibility in Travis County, Texas, USA. GeoJournal 51:245253.

Yalcin A (2008) GIS based landslide susceptibility mapping using analytical hierarchy process and bivariate statistics in Ardesen (Turkey): comparisons of results and confirmations. Catena 72:1-12.

Yalcin A, Reis S, Aydinoglu AC, Yomralioglu T (2011) A GIS-based comparative study of frequency ratio, analytical hierarchy process, bivariate statistics and logistics regression methods for landslide susceptibility mapping in Trabzon, NE Turkey. Catena 85(3):274-287.

Yoshimatsu $\mathrm{H}$, Abe S (2006) A review of landslide hazards in japan and assessment of their susceptibility using an analytical hierarchic process (AHP) method. Landslides 3:149-158.

Zadeh LA (1965) Fuzzy sets. Information and Control 8(3):338-353.

Zieher T, Perzl F, Rossel M, Rutzinger M, Meibl G, Markart G. Geitner C (2016) A multiannual landslide inventory for the assessment of shallow landslide susceptibility-Two test cases in vorarlberg, Austria. Geomorphology 259:4054.

\section{Figures}




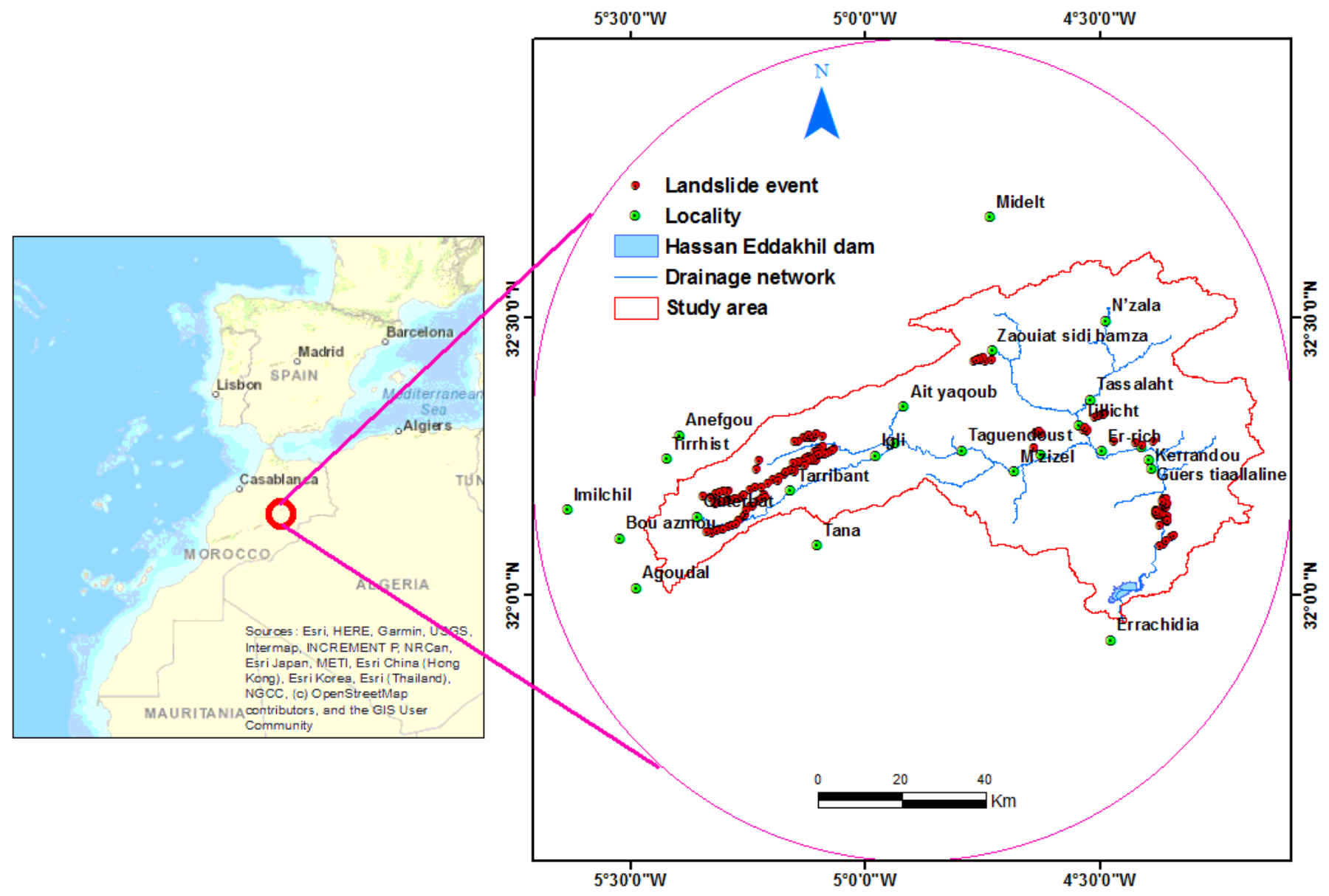

Figure 1

Location of the study area and landslide inventory map (red circle) 

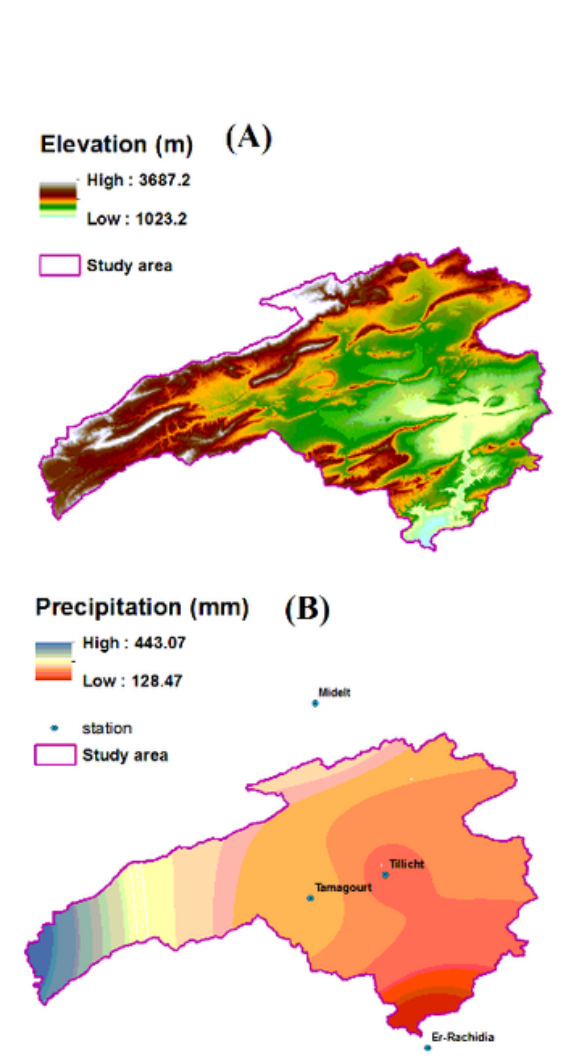

(C)

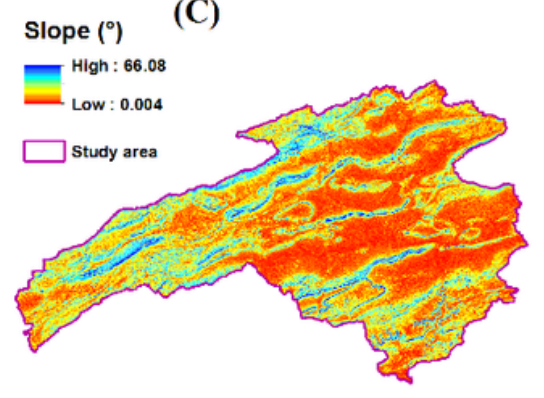

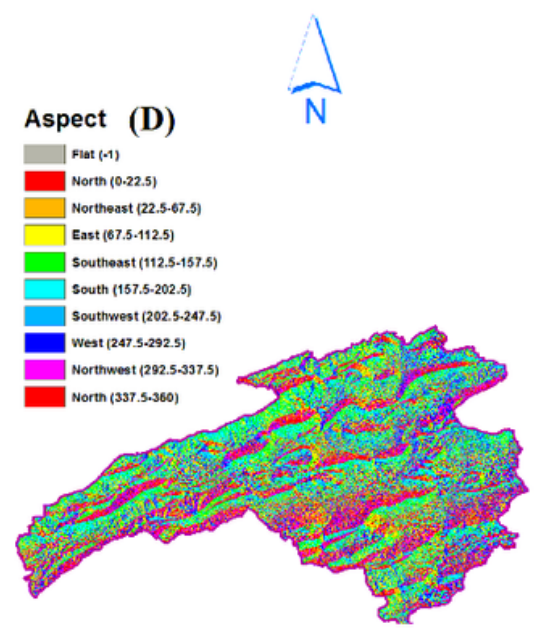

Geological map (E)
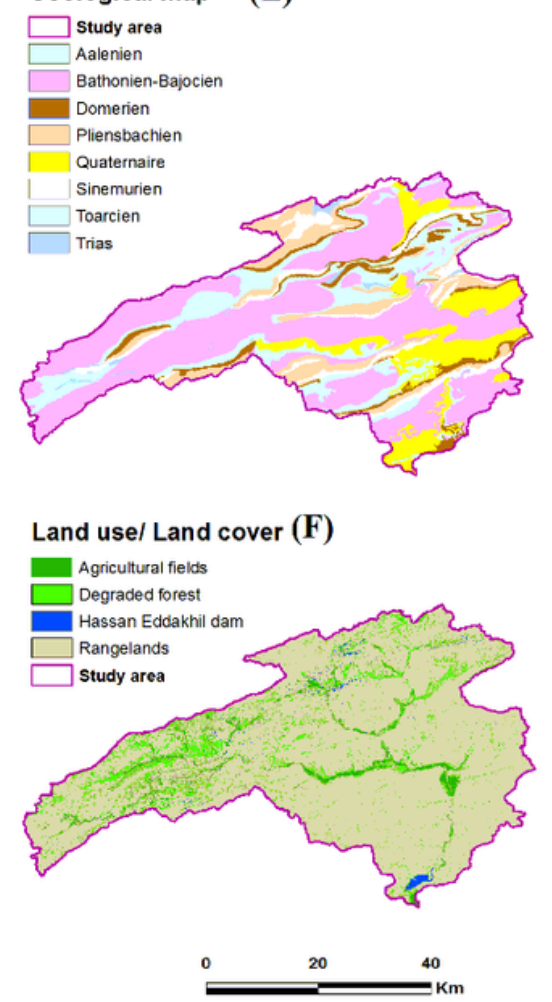

(G)

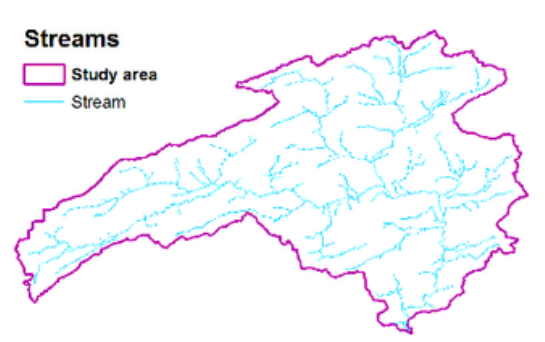

(H)

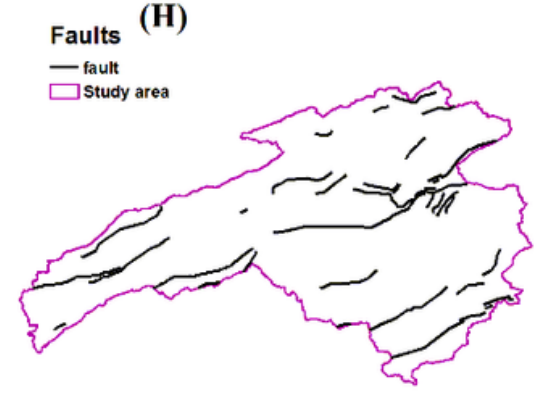

(I)

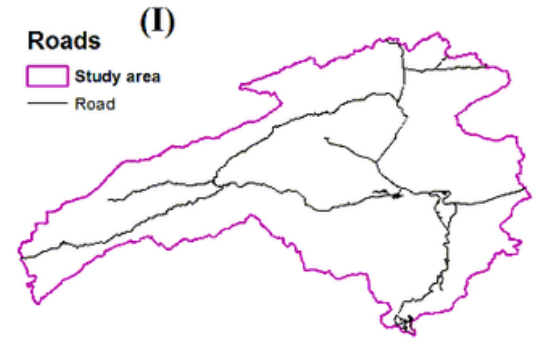

\section{Figure 2}

Raster maps used for LSM in this study: (A): DEM; (B): Rainfall; (C): Slope; (D): Aspect; (E): Lithology (Sensitivity); (F): LULC; (G): Streams; (H): Fault; (I): Road. 


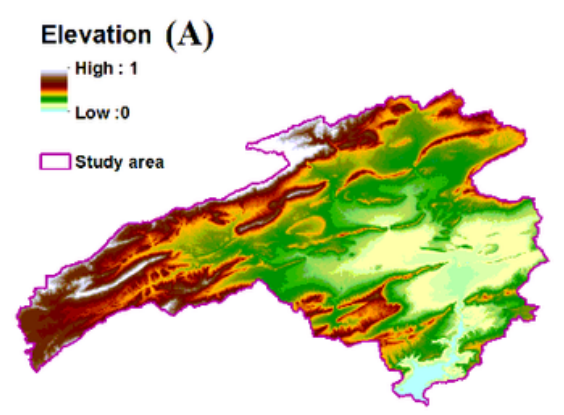

Rainfall (B)
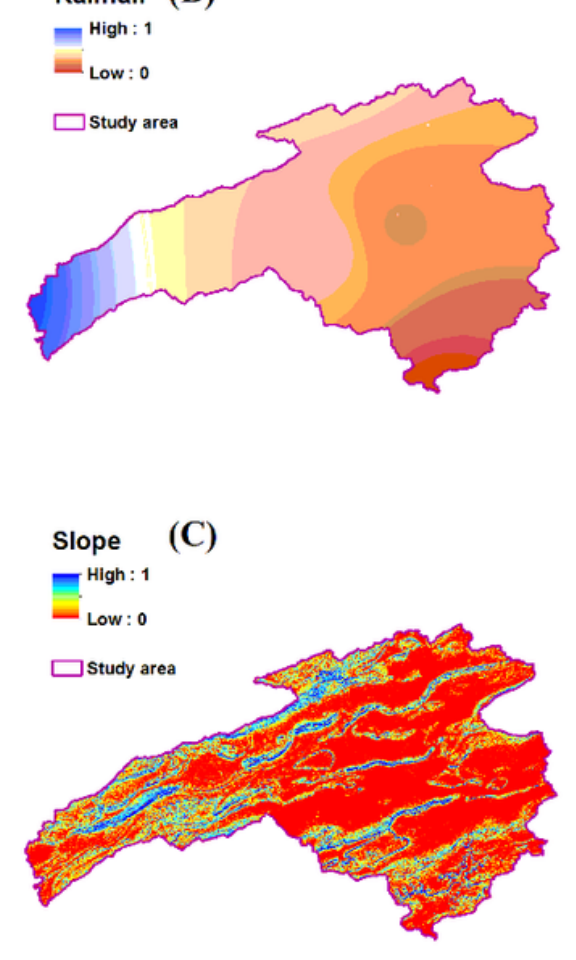

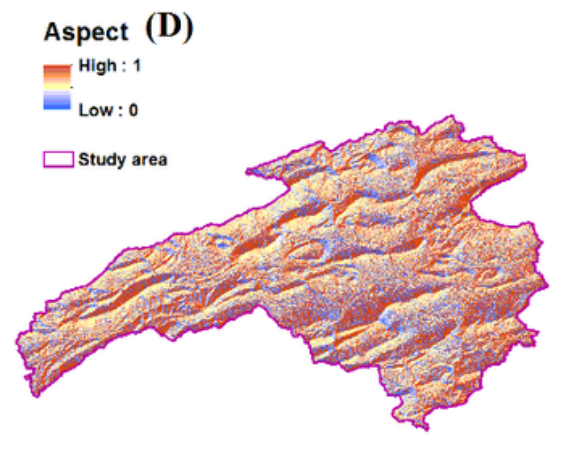

(E)
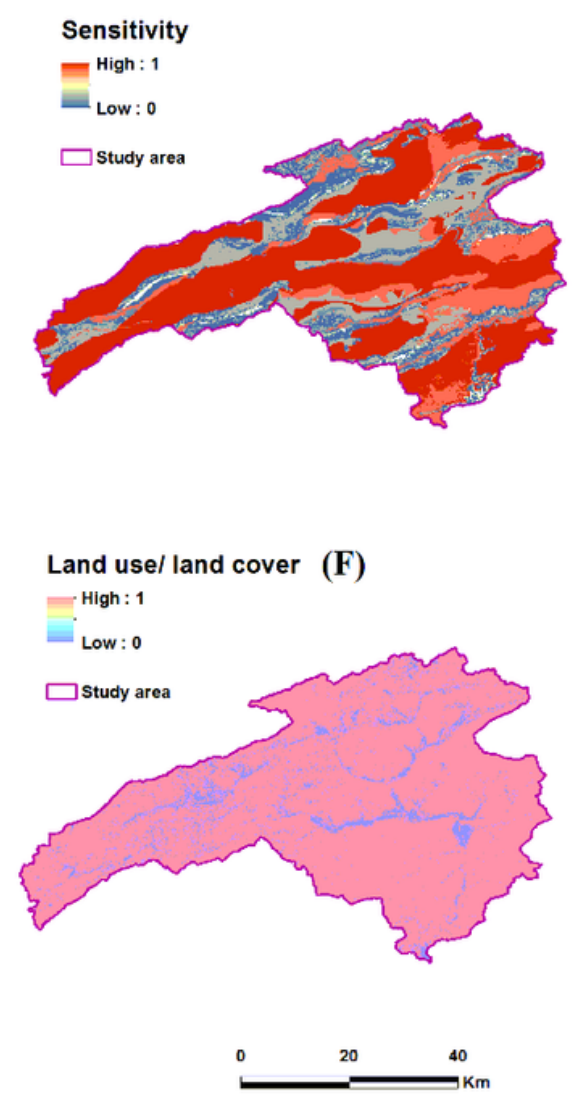
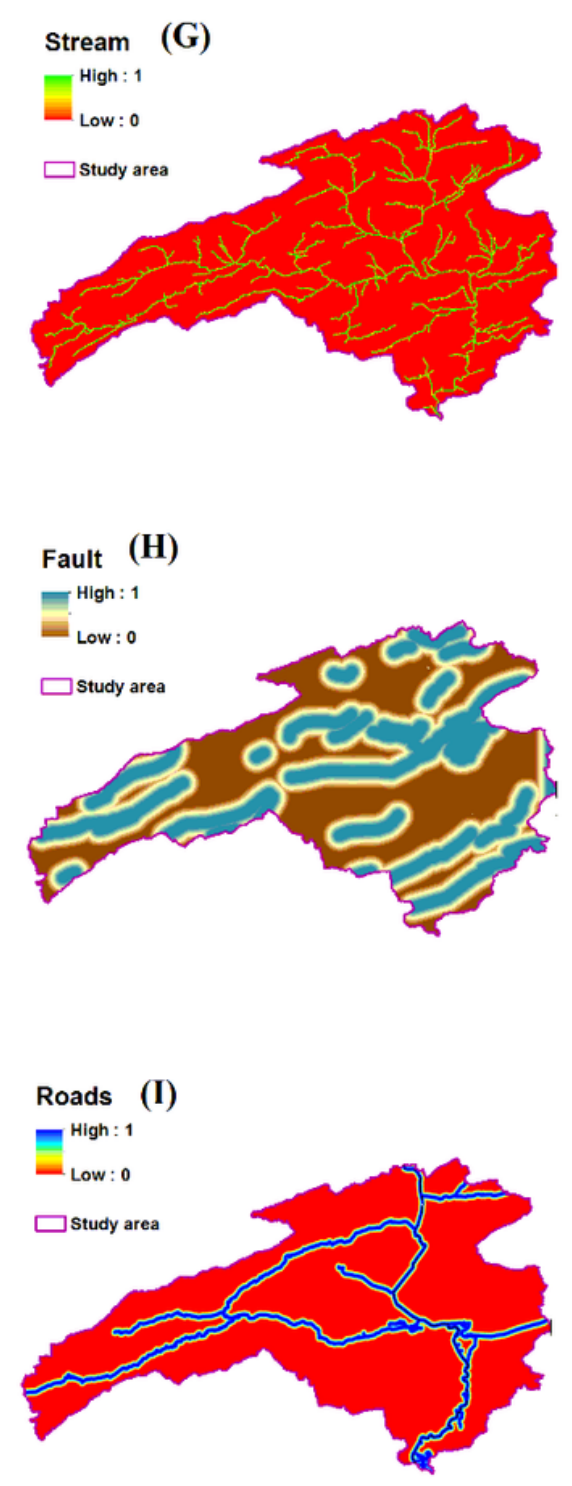

\section{Figure 3}

Fuzzy map of studied area for each landslide susceptibility parameter: (A): DEM; (B): Rainfall; (C): Slope; (D): Aspect; (E): Lithology (Sensitivity); (F): LULC; (G): Streams; (H): Fault; (I): Road. 


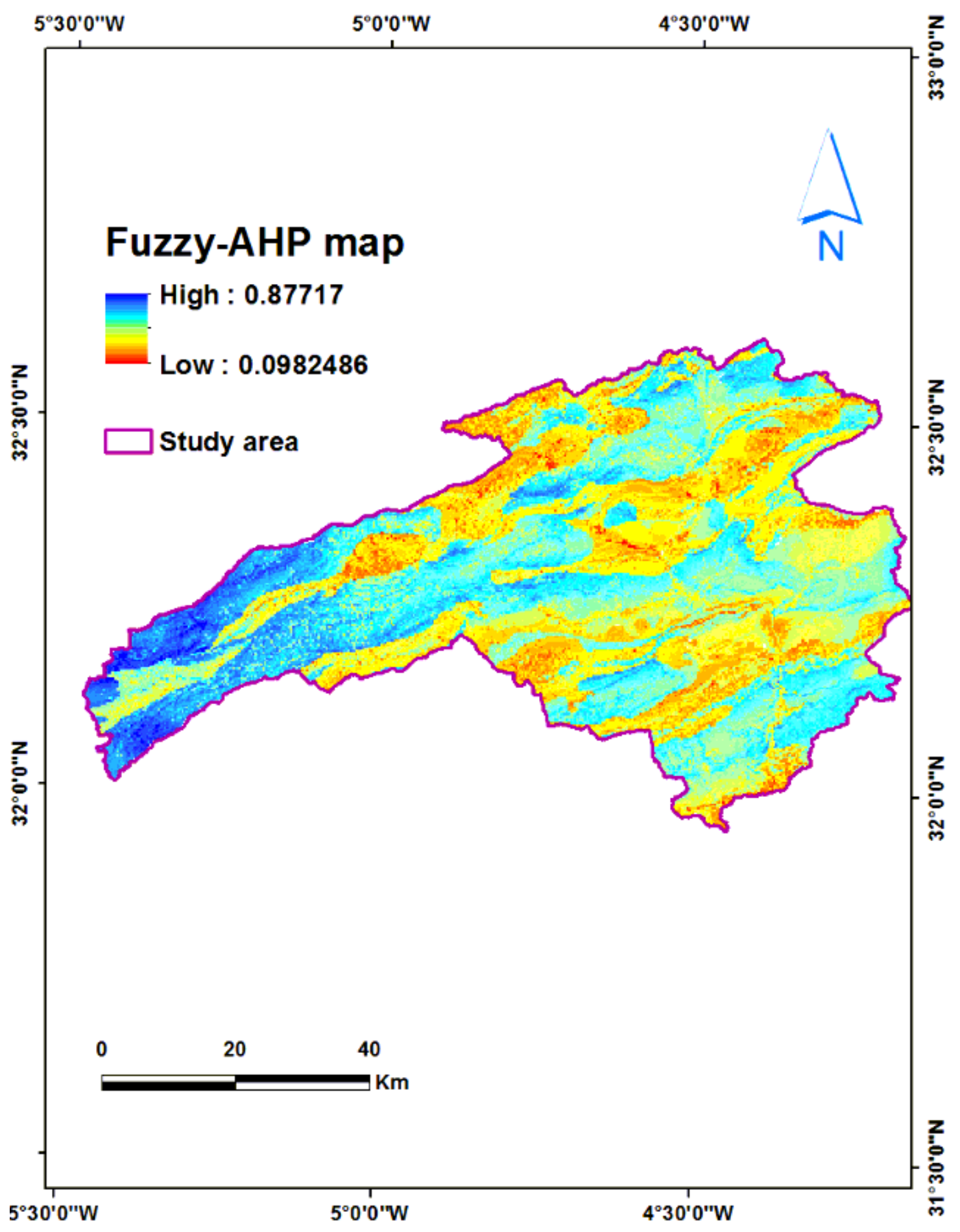

Figure 4

Landslide susceptibility map based on FAHP model 


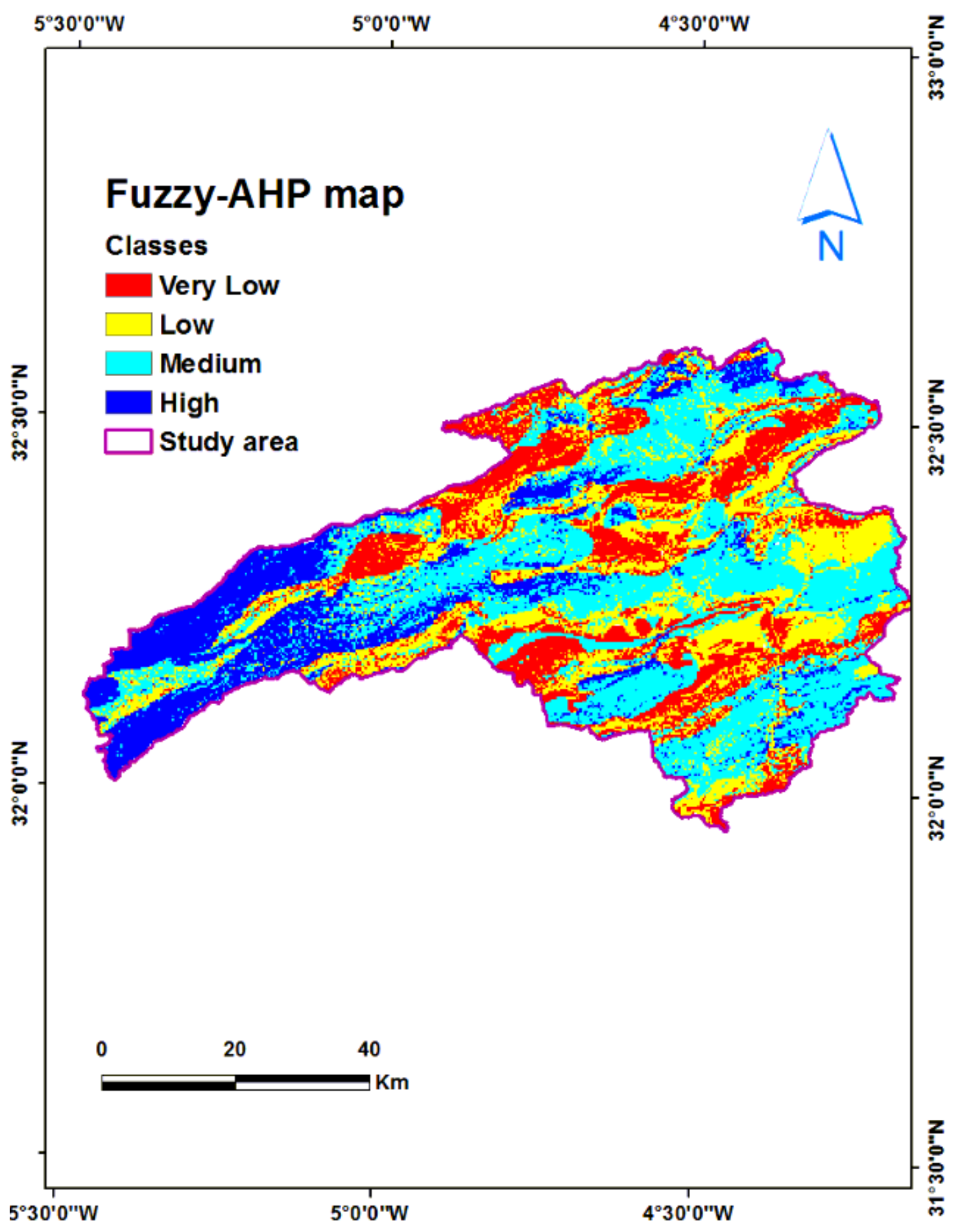

Figure 5

Classified landslide susceptibility map based on FAHP model 


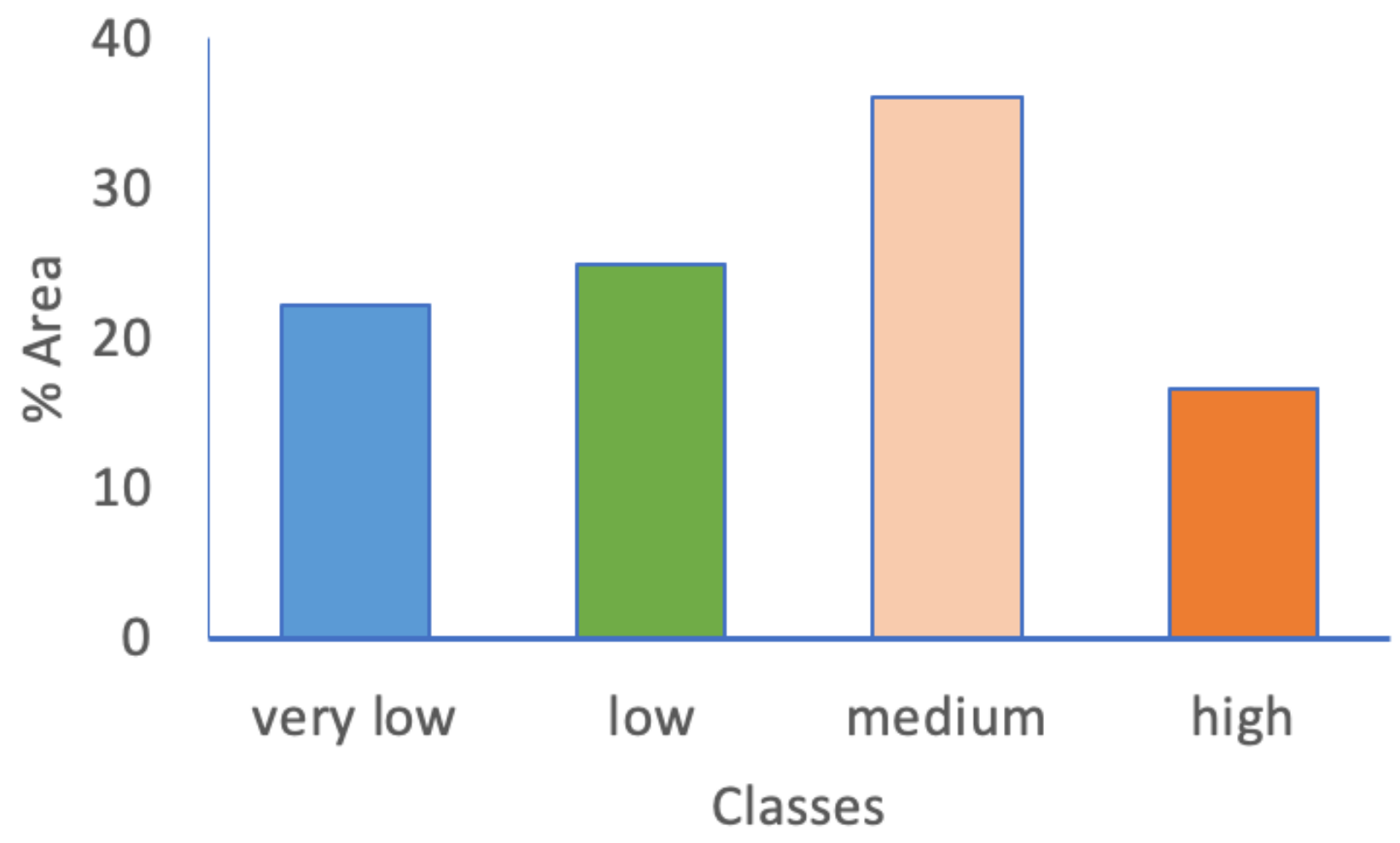

Figure 6

The area (\%) for each class of the landslide susceptibility 


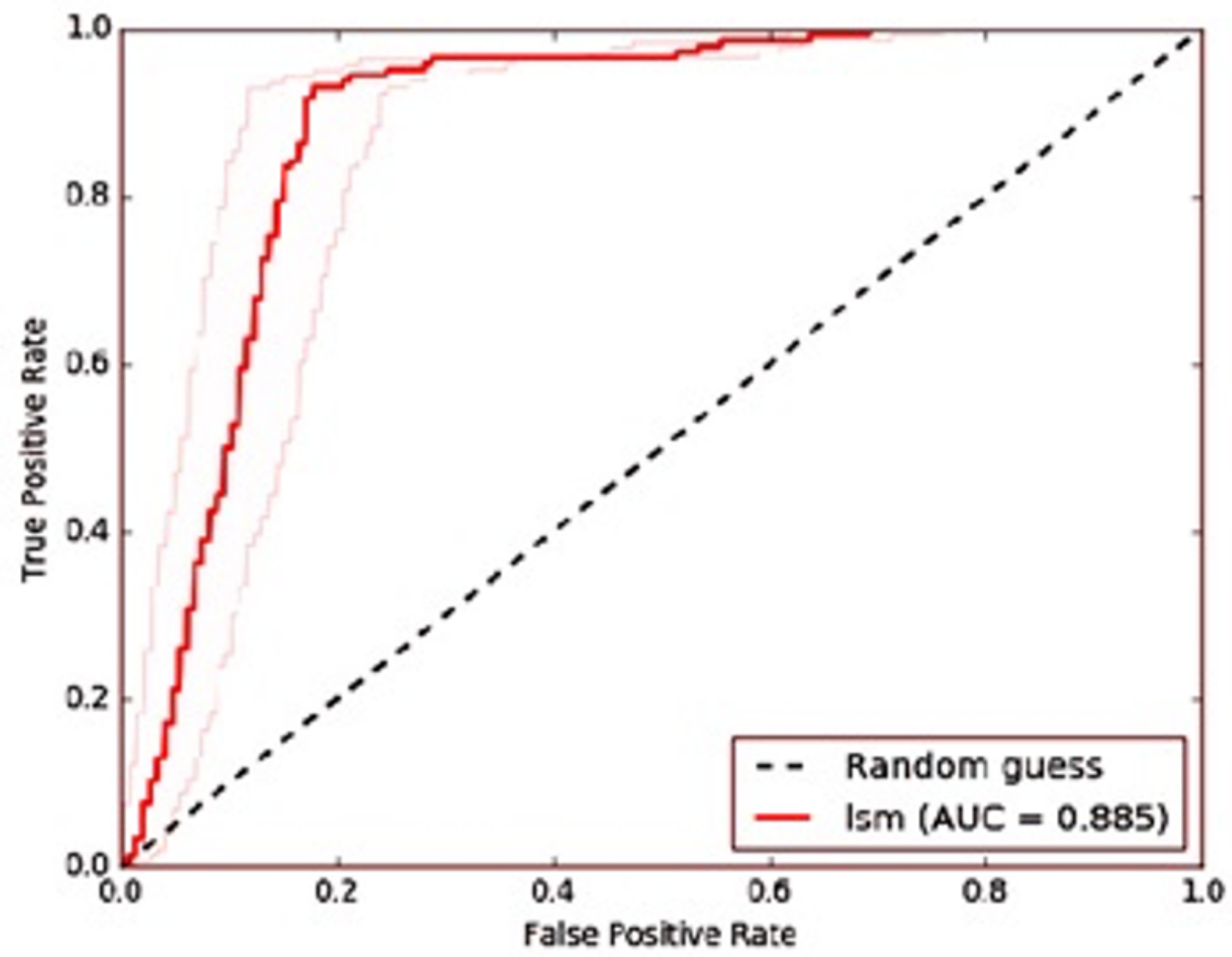

Figure 7

Prediction rate curve for the LSM produced by FAHP model. 